\title{
Flaccid paraplegia: a feature of spinal cord lesions in Holmes-Adie syndrome and tabes dorsalis
}

\author{
M. SWASH ${ }^{1}$ AND C. J. EARL ${ }^{2}$ \\ From the Department of Neurology, Section of Neurological Sciences, \\ The London Hospital, London
}

SYNOPSIS In a patient with Holmes-Adie syndrome, and in another with tabes dorsalis, a transverse cord lesion resulted in a severe, but flaccid paraplegia with absent tendon reflexes. Flexor spasms were severe in both patients, but spasticity was absent. The significance of these observations is discussed in relation to the functional and anatomical disorder in these two syndromes.

Spasticity is usually a prominent feature of paraplegia due to spinal cord disease, although a number of factors, especially poor nutritional state, extensive injuries, or severe infections, may delay its appearance or lessen its severity. Indeed, the association of spasticity with spinal cord disease is so characteristic that its presence, in a patient with paraplegia, is often taken as evidence that the causative lesion is at a spinal level.

In this paper we describe a patient with Holmes-Adie syndrome (Holmes, 1931; Adie, 1932) in whom, despite an almost complete paraplegia due to a compressive thoracic cord lesion, spasticity was absent, and a second patient, with tabes dorsalis and a severe coincidental cord lesion, in whom a similar clinical picture was seen. In both patients the tendon reflexes were absent but both developed severe flexor spasms. The significance of these observations will be discussed in relation to the functional abnormality in the spinal cord in these patients and in patients with spasticity.

\section{CASE 1 (LH 37364/50)}

HOLMES-ADIE SYNDROME: PARAPLEGIA DUE TO CORD COMPRESSION A 60 year old woman was admitted complaining of difficulty in walking. For 18 months she had noticed backache in the mid-thoracic region and for about a year she had experienced tingling in

1 Requests for reprints: Dr M. Swash, Department of Neurological Sciences, The London Hospital, London E1 1BB.

2 Present address: The National Hospital for Nervous Diseases, Queen Square, London W.C.1.

(Accepted 14 November 1974.) her legs. This tingling sensation had gradually spread up from her feet to the lower trunk. For three months she had noticed that her right leg dragged when she walked.

On examination the gait was unsteady. There was moderate weakness of the right leg, most evident in hip flexion and in dorsiflexion of the foot. Tone was normal in both legs. The tendon reflexes were absent in the arms and legs, even with reinforcement, and both plantar responses were extensor. There was sensory impairment to pin prick and to light touch below T11 dermatome on both sides. Pin prick sensibility was more impaired in the left leg than the right and joint position sense was absent in the right foot and impaired in the left. Vibration sense was absent in both legs but was present at the knees. The pupils were small, slightly irregular, and unequal. There was no pupillary reaction to light or accommodation with ordinary clinical tests but in a dark room both pupils gradually dilated and slow, tonically maintained reactions to both light and accommodation could then be demonstrated. Sweating was normal and there was no postural hypotension. Absence of the tendon reflexes and tonic pupillary reactions had first been observed during a routine medical examination at the age of 17 years.

Radiographs of the thoracic spine showed a faintly calcified shadow at the level of the body of T9 vertebra and a lumbar myelogram showed an incomplete extradural block to the flow of contrast at this level. The CSF contained one lymphocyte $/ \mathrm{mm}^{3}$ and $40 \mathrm{mg}$ protein/dl. The WR was negative in blood and CSF. Laminectomy was performed and an extradural meningioma which had compressed the cord was removed. Postoperatively the motor and sensory symptoms in her legs improved. 
Progress A year later she was readmitted. During the previous few weeks her legs had gradually become weaker so that she could walk only with a stick. On examination there was a moderately severe paraparesis. Both plantar responses were extensor and occasional flexor spasms were observed in the legs, but tone was flaccid and all the tendon reflexes were absent. Light touch was impaired below the knees and joint position sense and vibration sense were impaired in the feet. Pin prick sensibility was normal in both legs. The laminectomy incision was tender. At exploration, an extensive multilocular extradural abscess was drained and a thick layer of granulation tissue at the site of the dural repair was excised. There was no recurrence of the tumour.

She was treated with a prolonged course of antibiotics but in the following six months she became unable to walk, and was then incapacitated by painful, prolonged flexor spasms in both legs. At this time muscular tone was flaccid in both legs, but painful or tickling stimuli applied to the feet or shins provoked severe and repeated flexor spasms; both plantar responses were extensor. All the tendon reflexes were absent. There was a profound alteration of joint position sense and of vibration sense in both legs to the level of the hips, although pin prick and light touch were abnormal only in the feet. A cisternal myelogram showed a complete block to the flow of contrast medium at T9 vertebra. The laminectomy wound was therefore re-explored. The subarachnoid space was obliterated by dense fibrous tissue which was closely adherent to the posterior part of the cord at T9-L1 vertebral levels. The cord itself appeared brownish and atrophic. Postoperatively there was some improvement in strength in her legs and the flexor spasms became less troublesome.

Present state Eight years after the first operation she is able to stand with support and can transfer from chair to bed using her arms. There is severe paraparesis but muscular tone is flaccid: there is no spasticity. The right leg is slightly stronger than the left. The tendon reflexes are all absent, even with reinforcement. Both plantar responses are extensor, and the reflexogenous zone extends proximally to the mid-thigh on each side. Flexor spasms can be elicited readily by painful stimuli applied to the legs, and especially by noxious plantar stimulation, but extensor spasms have never been observed. Position and vibration sense are impaired to the level of the hips, particularly on the right side, and there is slight impairment of pin prick sensibility in both feet. Light touch is impaired to the lower thoracic level. She is incontinent of urine. The pupillary abnormality is unchanged.
Other investigations The $\mathbf{H}$ response, a monosynaptic phasic reflex, was studied using the method of Mayer and Mawdsley (1965). There was no detectable $\mathrm{H}$ response in either calf at rest, during reinforcement with the Jendrassik manoeuvre (Landau and Clare, 1964a), or after a conditioning tetanus applied to the medial popliteal nerve in the popliteal fossa (Corrie and Hardin, 1964).

The tonic vibration reflex was studied in the legs using a technique established as part of a previous investigation (Crawley et al., 1973). It was also studied in the arms using a portable vibrator (see Marsden et al., 1969). No response was observed to stimuli of $30-600 \mathrm{~Hz}$ in either arm or leg. In the legs the vibratory stimulus sometimes elicited a flexor spasm, a reflex with a more rapid time course than that of the tonic vibration reflex itself.

Electromyography of quadriceps, biceps femoris, and gastrocnemius muscles showed no evidence of denervation, and the medial and lateral popliteal sensory and motor nerve conduction velocities were normal.

\section{CASE 2 (LH 21034/49)}

TABES DORSALIS: PARAPLEGIA DUE TO SYPHILITIC MYELITIS This man contracted syphilis in 1911, aged $\delta$ 음 18 years. He was discharged from the Army in 1917 because of tabes dorsalis. At that time he was seen at $\overrightarrow{0} \cdot \vec{\varphi}$ The London Hospital by Dr Henry Head who noted that the patient had lightning pains in his legs, that there was bilateral ptosis with Argyll Robertson pupils, and that both plantar responses were extensor. In 1927 he complained of weakness in his legs. This progressed and in 1936 he was admitted under the care of Dr George Riddoch, who found a moderately severe, but hypotonic, paraparesis with extensor plantar responses. In the legs the tendon reflexes were absent and there was impairment of joint position sense, vibration sense, and deep pain. Superficial painful stimuli were appreciated only after a short delay.

During 1945 the weakness worsened more rapidly and, in 1946, Dr Russell Brain found a very severe flaccid paraplegia. The patient could scarcely lift his legs from the bed. All the tendon reflexes in the legs were absent, and both plantar responses were extensor. There was bilateral impairment of light touch and pin prick sensibility below the C8 dermatomes, and a profound disturbance of position sense in ankles, knees, and hips. Flexor spasms could be induced by minor painful stimuli to the legs. There was a neurogenic bladder. Syphilitic optic atrophy was noted. The arms were normal.

A diagnosis of tabes dorsalis with syphilitic meningomyelitis was made and he was treated with 
parenteral penicillin. In 1958, however, there was a complete paraplegia, interrupted by frequent, spontaneous flexor spasms. The tendon reflexes remained absent in both legs and both plantar responses were extensor. Tone in the legs was flaccid. He died in 1960, aged 67 years.

\section{DISCUSSION}

It was remarkable that, in both our patients, despite functionally almost complete transverse cord lesions, spasticity was absent and the tendon reflexes could not be elicited, although the anterior horn cells at the same segmental levels were easily excitable by cutaneous input from group II and group III afferent fibres, resulting in flexor spasms. The anterior horn cells seem to have been refractory only to input from group Ia fibres-it is not possible to draw conclusions about the effect of group Ib fibre input. This apparently complete refractoriness to phasic input from the muscle spindle primary afferent system, even in the presence of a transverse cord lesion, is not entirely unexpected in tabes dorsalis, since it was associated with other sensory abnormalities typical of a disorder of large, thickly myelinated, afferent fibres, and it is consistent with the usual pathological findings in this disease. However, its pathophysiological basis in Holmes-Adie syndrome is more difficult to understand.

It is first necessary to consider what is the functional disorder underlying the absence of phasic tendon reflexes in otherwise normal subjects with Holmes-Adie syndrome. Hardin and Gay (1965) and McComas and Payan (1966), studying this problem, found that the H-responses were absent or decreased in amplitude roughly in parallel with the abnormality in the tendon reflexes. When the $\mathrm{H}$-reflexes were absent, as in our patient, prior tetanization of the medial popliteal nerve was ineffective in conditioning their reappearance (Hardin and Gay, 1956). Nonetheless, reflex reinforcement by the Jendrassik manoeuvre will sometimes bring out otherwise absent tendon reflexes in this condition. This manoeuvre increases the excitability of alpha motoneurones, but probably does not increase fusimotor drive (Landau and Clare, 1964a). These studies suggest that in HolmesAdie syndrome there is decreased excitability of alpha motoneurones to synchronous afferent volleys.

McComas and Payan (1966), reviewing the possible causes of this decreased excitability, suggested that it might be due, firstly, to increased pre-synaptic inhibition by interneurones acting on the Ia terminals, or secondly, to increased post-synaptic inhibition of alpha motoneurones by Renshaw cells, or by other interneurones, reflecting input either from Golgi tendon organs or from primary sensory endings in muscle spindles situated in antagonist muscles. Thirdly, it might be due to other, unspecified, segmental or descending inhibitory influences.

Decreased excitability of anterior horn cells might explain the absence preoperatively of spasticity in our patient, although it is surprising that inhibition of stretch reflexes of this degree could be maintained in the presence of an almost complete, suprasegmental, transverse lesion. The absence of the tonic vibration reflex in our patient must be interpreted with caution since this reflex is sometimes absent in normal subjects (Marsden et al., 1969) and, further, it has not been studied in otherwise normal subjects with Holmes-Adie syndrome.

Spasticity is an abnormal increase in muscle tone which occurs in response to stretch of a muscle. It is usually more marked in response to rapid than to slow stretches. Spasticity is associated with increased excitability of alpha motoneurones (Landau and Clare, 1964b; Dimitrijević and Nathan, 1967a) due to loss of descending inhibitory input, and in some patients, perhaps especially those with cerebral lesions, it may also be associated with increased fusimotor drive (Dimitrijevic and Nathan, 1967b; Herman, 1970; Burke et al., 1971). The precise pathophysiology of spasticity resulting from lesions at various levels in the nervous system is controversial (see Landau, 1969; Nathan, 1970). Burke and Ashby (1972) have suggested that it may be due, in part, to decreased pre-synaptic inhibition at the Ia synapse with the anterior horn cells, since inhibition of the stretch reflex by vibration was less marked in patients with spasticity than in normal subjects. This view is consistent both with McComas and Payan's (1966) proposal that in Holmes-Adie syndrome there is increased presynaptic inhibi- 
tion at this site, and with the absence of spasticity in our patient.

It has been suggested that the Holmes-Adie syndrome may be due to degenerative lesions in both the ciliary ganglia and the spinal cord (Holmes, 1931; Adie, 1932; Leathart, 1942). Only two necropsies have been reported (Ruttner, 1947; Harriman and Garland, 1968). In both, the spinal cord was normal but loss of neurones in the ciliary ganglia was described and it was suggested that there were similar changes in the posterior root ganglia. However, interpretation of neuronal loss in posterior root ganglia is difficult (see Greenfield, 1958) and a lesion at this site, or in the innervation of the muscle spindles, as was suggested by Harriman and Garland (1968), would not account for the physiological abnormalities.

It is striking that, in the Holmes-Adie syndrome, despite the absence of tendon reflexes, both muscle tone and the capacity to perform and to learn complex voluntary movements are normal. Marsden et al. (1973) have recently pointed out that the phasic stretch reflex, part of which is assessed by the tendon jerk, is only a fraction of the whole stretch reflex (see Sherrington, 1924). Tonic responses to slow stretches, whose reflex arc may involve cortical structures, must also be considered. These tonic responses to stretch, which are probably important in motor control, both in its acquisition and its performance, may be preserved in this syndrome.

The location of the lesion responsible for absence of the tendon reflexes in tabes dorsalis is controversial. Changes have been described in the posterior root entry zone in the cord, and in the posterior root ganglia (see Wilson, 1940; Greenfield, 1958), but abnormalities also occur in the primary and secondary sensory endings in the muscle spindles (Swash and Fox, 1974). This combination of central and peripheral disturbances may account for the occasional reappearance of the tendon reflexes in the legs after the occurrence of a hemiplegia in a tabetic (Jackson and Taylor, 1891). In our patient, however, the reflexes remained absent and spasticity did not appear. Paraplegia in spinal syphilis was formerly not uncommon. Paraplegia supervening in a tabetic was often flaccid, and in such patients the tendon reflexes usually remained absent. This clinical picture was sometimes referred to as 'tabes combinée'. Examples of several such patients may be found in Head and Fearnsides' review of the clinical features of neurosyphilis (Head and Fearnsides, 1914), and in Wilson's textbook (Wilson, 1940). In other patients, however, in whom the tendon reflexes were exaggerated, spasticity was sometimes very marked, as in Erb's paraplegia (Wilson, 1940). Even in uncomplicated tabes, motor control is not normal. Although this is usually ascribed directly to the defect of 'posterior column sensation' its explanation may be more complex, particularly in view of the pathological findings. In these respects, the functional disorder in tabes dorsalis is clearly different from that found in Holmes-Adie syndrome, although in both our patients spasticity was absent and flexor spasms were released.

Flexor spasms, which were a significant source of disability in both our patients, are polysynaptic spinal reflexes which commonly appear after spinal cord lesions in man. They are usually associated with signs of both corticospinal and posterior column disease as in the "paraplegiain-flexion' of multiple sclerosis, taboparesis, or subacute combined degeneration of the cord. In these diseases small-diameter, afferent nerve fibres are relatively spared. Flexor spasms are analogous to the nociceptive flexor reflex described by Sherrington in the decerebrate cat, and the extensor plantar response is itself part of this reflex (Walshe, 1956). It is well known that flexor spasms may become more severe in the presence of decubitus ulcers, superficial infections, and urinary tract infections. These disorders result in increased input to the cord through group II and group III fibres of the 'flexor reflex afferent pathway' (see Lundborg, 1966), resulting in activation of the flexor reflex. The presence of severe flexor spasms, at a time when spasticity was absent, indicates, therefore, that polysynaptic pathways at segmental level in the cord were intact, and provides further evidence that the anterior horn cells were refractory only to input from group Ia afferents. Dissociation of flexor spasms from spasticity is an unusual clinical observation which is, perhaps, best known as a transient phenomenon during recovery from spinal shock as, for example, after traumatic transection of the cord (Head and Riddoch, 1917). 
There has been considerable recent interest in the treatment of spasticity but none of the available drugs or surgical techniques is entirely satisfactory. Moreover, the site of action of the various available drugs is poorly understood. Our observations in these two patients suggest that it may yet be possible to alleviate spasticity without causing impairment of voluntary movement.

\section{REFERENCES}

Adie, W. J. (1932). Tonic pupils and absent tendon reflexes: a benign disorder sui generis; its complete and incomplete forms. Brain, 55, 98-113.

Burke, D., Andrews, C. J., and Gillies, J. D. (1971). The reflex response to sinusoidal stretching in spastic man. Brain, 94, 455-470.

Burke, D., and Ashby, P. (1972). Are spinal 'presynaptic' inhibitory mechanisms suppressed in spasticity? Journal of the Neurological Sciences, 15, 321-326.

Corrie, W. S., and Hardin, W. B., Jr (1964). Post-tetanic potentiation of $\mathrm{H}$ reflex in normal man. Archives of Neurology (Chic.), 11, 317-323.

Crawley, F. E. H., Kennedy, P., and Swash, M. (1973). Effect of dimethothiazine on tonic vibration reflex in man. British Journal of Pharmacology, 47, 613-614P.

Dimitrijević, M. R., and Nathan, P. W. (1967a). Studies of spasticity in man. 1. Some features of spasticity. Brain, 90, $1-30$.

Dimitrijević, M. R., and Nathan, P. W. (1967b). Studies of spasticity in man. 2. Analysis of stretch reflexes in spasticity. Brain, 90, 333-358.

Greenfield, J. G., Blackwood, W., McMenemey, W. H., Meyer, E., and Norman, R. M. (1958). Infectious diseases of the central nervous system. In Neuropathology, pp. 132229. Arnold: London.

Hardin, W. B., Jr, and Gay, A. J. (1965). The phenomenon of benign areflexia. Review of the Holmes-Adie syndrome with case reports and a study of the Achilles reflex. Neurology (Minneap.), 15, 613-621.

Harriman, D. G. F., and Garland, H. (1968). The pathology of Adie's syndrome. Brain, 91, 401-418.

Head, H., and Fearnsides, E. G. (1914). The clinical aspects of syphilis of the nervous system in the light of the Wassermann reaction and treatment with neosalvarsan. Brain, 37, 1-140.

Head, H., and Riddoch, G. (1917). The automatic bladder, excessive sweating and some other reflex conditions, in gross injuries of the spinal cord. Brain, 40, 188-263.
Herman, R. (1970). The myotatic reflex. Clinico-physiological aspects of spasticity and contracture. Brain, 93, 273-312.

Holmes, G. (1931). Partial iridoplegia associated with symptoms of other disease of the nervous system. Transactions of the Ophthalmological Society of the United Kingdom, 51, 209-228.

Jackson, J. H., and Taylor, J. (1891). Remarks on a case of return of knee-jerks after hemiplegia in a tabetic. British Medical Journal, 2, 57-58.

Landau, W. M. (1969). Spasticity and rigidity. In Recent Advances in Neurology, pp. 1-32. Edited by F. Plum. Davis: Philadelphia.

Landau, W. M., and Clare, M. H. (1964a). Fusimotor function. Part 4. Reinforcement of the $\mathrm{H}$ reflex in normal subjects. Archives of Neurology (Chic.), 10, 117-122.

Landau, W. M., and Clare, M. H. (1964b), Fusimotor function. Part 6. H reflex, tendon jerk, and reinforcement in hemiplegia. Archives of Neurology (Chic.), 10, 128-134.

Leathart, P. W. (1942). The tonic pupil syndrome. British Journal of Ophthalmology, 26, 60-64.

Lundborg, A. (1966). Integration in the reflex pathway. In Muscular Afferents and Motor Control. First Nobel Symposium, pp. 275-305. Edited by R. Granit. Almqvist and Wiksell: Stockholm.

McComas, A. J., and Payan, J. (1966). Motoneurone excitability in the Holmes-Adie syndrome. In Control and Innervation of Skeletal Muscle, pp. 182-195. Edited by B. L. Andrew. University of St Andrews: Dundee.

Marsden, C. D., Meadows, J. C., and Hodgson, H. J. F. (1969). Observations on the reflex response to muscle vibration in man and its voluntary control. Brain, 92, 829846.

Marsden, C. D., Merton, P. A., and Morton, H. B. (1973). Is the human stretch reflex cortical rather than spinal? Lancet, 1, 759-761.

Mayer, R. F., and Mawdsley, C. (1965). Studies in man and cat of the significance of the $\mathrm{H}$ wave. Journal of Neurology, Neurosurgery, and Psychiatry, 28, 201-211.

Nathan, P. W. (1970). Spasticity and its amelioration. In Modern Trends in Neurology, vol. 5, pp. 41-59. Edited by D. Williams. Butterworths: London.

Ruttner, F. (1947). Die tonische Pupillenreaktion. Klinische und anatomische Untersuchungen. Monatsschrift für Psychiatrie und Neurologie, 114, 265-330.

Sherrington, Sir Charles C. (1924). Problems of muscular receptivity. Nature, 113, 892-894, and 929-932.

Swash, M., and Fox, K. P. (1974). The pathology of the human muscle spindle: effect of denervation. Journal of the Neurological Sciences, 22, 1-24.

Walshe, Sir Francis (1956). The Babinski plantar response, its forms and its physiological and pathological significance. Brain, 79, 529-556.

Wilson, S. A. K. (1940). Diseases of the Nervous System. vol. 1. Arnold: London. 